\title{
Performance of multispecies assessment models: insights on the influence of diet data
}

Trijoulet, Vanessa; Fay, Gavin; Curti, Kiersten L.; Smith, Brian; Miller, Timothy J.

Published in:

ICES Journal of Marine Science

Link to article, DOI:

10.1093/icesjms/fsz053

Publication date:

2019

Document Version

Peer reviewed version

Link back to DTU Orbit

Citation (APA):

Trijoulet, V., Fay, G., Curti, K. L., Smith, B., \& Miller, T. J. (2019). Performance of multispecies assessment models: insights on the influence of diet data. ICES Journal of Marine Science, 76(6), 1464-1476. [fsz053]. https://doi.org/10.1093/icesjms/fsz053

\section{General rights}

Copyright and moral rights for the publications made accessible in the public portal are retained by the authors and/or other copyright owners and it is a condition of accessing publications that users recognise and abide by the legal requirements associated with these rights.

- Users may download and print one copy of any publication from the public portal for the purpose of private study or research.

- You may not further distribute the material or use it for any profit-making activity or commercial gain

- You may freely distribute the URL identifying the publication in the public portal 


\title{
Performance of multispecies assessment models: insights on the influence of diet data
}

\author{
Vanessa Trijoulet (D) ${ }^{1 *, \neq}$, Gavin Fay ${ }^{2}$, Kiersten L. Curti ${ }^{1}$, Brian Smith ${ }^{1}$, and Timothy J. Miller ${ }^{1}$ \\ ${ }^{1}$ Northeast Fisheries Science Center, National Marine Fisheries Service, National Oceanic and Atmospheric Administration, 166 Water St., Woods \\ Hole, MA 02543, USA \\ ${ }^{2}$ Department of Fisheries Oceanography, School for Marine Science and Technology, University of Massachusetts Dartmouth, New Bedford, MA, \\ USA
}

*Corresponding author: tel: + 145358834 54; fax: + 145 (0) 358833 33; e-mail: vtri@aqua.dtu.dk.

" Present address: Section for Marine Living Resources, National Institute of Aquatic Resources, Technical University of Denmark, Kemitorvet, DK-2800 Kgs. Lyngby, Denmark

Trijoulet, V., Fay, G., Curti, K. L., Smith, B., and Miller, T. J. Performance of multispecies assessment models: insights on the influence of diet data. - ICES Journal of Marine Science, doi:10.1093/icesjms/fsz053.

Received 11 October 2018; revised 1 March 2019; accepted 4 March 2019.

Multispecies stock assessment models require predator diet data, e.g. stomach samples. Diet data can be unavailable, sparse, of small sample size, or very noisy. It is unclear if multispecies interactions can be estimated without bias when interactions are weak. Research is needed about how model performance is affected by the availability or quality of diet data and by the method for fitting it. We developed seven agestructured operating models that simulate trophic interactions for two fish species and different scenarios of diet data availability or quality. The simulated data sets were fitted using four statistical catch-at-age models that estimated fishing, predation and residual natural mortality and differed in the way the diet data was fitted. Fitting the models to diet data averaged over time should be avoided since it resulted in estimation bias. Fitting annual diet composition per stomach produced bias estimates due to the occurrence of zeros in the observed proportions and the statistical assumptions for the diet model. Fitting to annual stomach proportions averaged across stomachs led to unbiased results even if the number of stomachs was small, the interactions were weak or some sampled years and ages were missing. These methods should be preferred when fitting multispecies models.

Keywords: ecosystem-based fisheries management, multispecies stock assessment, predator diet, simulation testing, statistical catch-at-age model, Template Model Builder

\section{Introduction}

There is an increasing incentive to develop ecosystem-based management approaches. While ecosystem-based management can take several forms, when the interest is on mixed fisheries with trophic interactions between the fish species, the term ecosystembased fisheries management (EBFM) is often used (Dolan et al., 2016). EBFM provides an integrated approach to ecosystem management (Link, 2010) and is strongly supported by numerous international agencies (FAO, 2003; NOAA, 2016). Multispecies models are becoming important tools for operationalizing EBFM approaches (Plagányi, 2007). These models estimate population dynamics while accounting for trophic interactions and are therefore a more realistic representation of the structure of the ecosystem than models where these dynamics are implicit.

Different levels of complexity exist in multispecies modelling. Whole ecosystem models, such as Atlantis (Fulton et al., 2004) or Ecopath with Ecosim (Christensen and Walters, 2004), are simulation models and predation is only informed empirically using diet data or the literature. These models are useful to understand certain functionality of the ecosystem or to test management 
scenarios (Fulton et al., 2014; Grüss et al., 2016; Weijerman et al., 2016). However, simulation models are not fully adequate for supporting tactical management advice since values of mortality rates and fish dynamics are necessary and model parameters should be estimated from empirical data. In this case, multispecies stock assessment models are more relevant. These assessment models are usually of moderate complexity and only focus on the components of the ecosystem which are biologically or economically relevant for addressing management questions (Plagányi et al., 2014). Development of these multispecies assessment models has increased with the popularity of EBFM and range from simple deterministic Multispecies Virtual Population Analysis (MSVPA) models (Helgason and Gislason, 1979; Tsou and Collie, 2001) to more complex statistical catch-at-age models (Lewy and Vinther, 2004; JuradoMolina et al., 2005; Kinzey and Punt, 2009; Curti et al., 2013).

Despite increased realism, multispecies assessment models have disadvantages compared to single species models. They are mathematically more complex and therefore model development and estimation is time consuming, and model validation can be challenging. By increasing the model complexity, there is also the concern of over-fitting which is important if the model is used for management predictions (Hawkins, 2004). Principally, one main problem that arises with multispecies models is the requirement for predator diet data to parameterize and inform trophic interactions among species. Diet data usually come from stomach content sampling during fishery independent surveys. However, the intensity of sampling within and between years can vary over time due to priority of other data collections or shifts in scientific objectives. Reduced sampling or inherently large variability among stomach observations at a given time point will presumably weaken statistical inferences for predation model parameters. Diet data may also be uninformative due to weak trophic interactions, possibly biasing parameter estimation. Model assumptions may also be important in terms of how best to fit diet data and how the observed diet data and corresponding predictions should be aggregated. Sparse diet data may be responsible for estimation bias in multispecies assessment models (Van Kirk et al., 2015), but it is unclear how aggregating these sparse data over time affects multispecies assessment model performance when compared to fitting to sparser, potentially noisier data that are closer to the original observations (Deroba, 2018).

Here, we investigate how quality and availability of diet data as well as diet model assumptions affect the performance of multispecies age-structured assessment models. A set of multispecies age-structured population models were developed and used as operating models to simulate data for different multispecies statistical catch-at-age models, with the aim of determining robustness of methods for aggregating diet data, and how use of diet data with different levels of information affects model performance. Our simulation study is applied to a model of two fish species with trophic interactions. The statistical catch-at-age models we created provide new insights on the performance of multispecies assessment models that are useful for providing tactical advice under EBFM approaches.

\section{Methods}

The simulation study comprised seven operating models (OMs) and four estimation models (EMs). The OMs are identical in all aspects except for how predator diet data are simulated. The EMs are all multispecies statistical catch-at-age models that differ in how the diet data inform the model. The multispecies models were developed using the $\mathrm{R}$ package ( $\mathrm{R}$ Core Team, 2018) Template Model Builder (TMB) (Kristensen et al., 2016).

\section{Operating models \\ Model structure}

We developed a general multispecies age-structured population model that also accounted for fishing. The model was closely related to MSVPA concepts (Andersen and Ursin, 1977; Helgason and Gislason, 1979). Annual total mortality $(Z)$ comprised of components due to fishing $(F)$, predation $(P)$, and other sources of natural mortality $(M)$ was parameterized as instantaneous rate:

$$
Z_{t, a i}=F_{t, a, i}+M_{t, a, i}+P_{t, a, i}
$$

Predation mortality at time $t$ for prey species $i$ of age $a$ was:

$$
P_{t, a, i}=\sum_{j=1}^{J} \sum_{b=1}^{B_{j}}\left(\mathrm{CR}_{b, j} N_{t, b, j} \frac{\vartheta_{t, a, i, b, j}}{\sum_{i=1}^{I} \sum_{a=1}^{A_{i}} \phi_{t, a, i, b, j}+\phi_{\text {other }_{t, b, j}}}\right),
$$

where $N_{t, b, j}$ is the abundance of predator species $j$ of age $b$ at time $t$. $J$ is the total number of predator species and $B$ is the maximum age of the predator (age plus group). We approximated annual predation using the abundance expected at the beginning of each annual time step. The per-capita consumption rate of a predator $(C R)$ corresponded to the annual amount of all prey consumed by the predator. The biomass of prey $i$ available to predator $j(\phi)$ was the product of prey suitability to the predator $(\vartheta)$ and biomass of the prey (product of prey numbers $N$ and weight $w$ ):

$$
\phi_{t, a, i, b, j}=\vartheta_{t, a, i, b, j} N_{t, a, i} w_{t, a, i}
$$

This corresponds to a type II functional response (Holling, 1959). Following MSVPA concepts, the suitability depends on a prey-specific component, the vulnerability $(\rho)$ of a prey to a predator and on a size-specific component, the predator size preference $(g)$, which are assumed independent:

$$
\vartheta_{t, a, i, b, j}=\rho_{i, j} g_{t, a, i, b, j}
$$

We assumed the preference of a given size was a scaled Gamma function between 0 and 1 of the log ratio of masses of predator and prey:

$$
g_{t, a, i, b, j}=\left(\frac{X_{t, a, i, b, j}}{\left(\alpha_{j}-1\right) \beta_{j}}\right)^{\alpha_{j}-1} e^{-\left(\frac{X_{t, a, i, b, j}-\left(\alpha_{j}-1\right) \beta_{j}}{\beta_{j}}\right)},
$$

where $\alpha_{j}$ and $\beta_{j}$ are shape and scale parameters, respectively, and $X_{t, a, i, b, j}=\log \left(w_{t, b, j} / w_{t, a, i}\right)$.

The function equals 1 at its maximum when $X_{t, a, i, b, j}=\left(\alpha_{j}-1\right) \beta_{j}$.

In the model, a predator cannot eat a prey of the same weight or bigger so $g=0$ in these cases. We assumed that biomass of food other than the modelled species was always of preferred size such that size preference for other food was 1 . As a result, suitability of other food only depended on its vulnerability and the available biomass of other food ( $\left.\phi_{\text {other }}\right)$ was:

$$
\phi_{\text {other }_{t, b, j}}=\rho_{\text {other }_{j}} \text { BIOM }_{\text {other }_{j}} \text {, }
$$

where the biomass of other food $\left(\mathrm{BIOM}_{\mathrm{other}}\right)$ was assumed to be a known constant. 
Vulnerability varies with biological and physical constraints such as habitat overlap, prey, and predator behaviors or depth (Gislason and Helgason, 1985). Vulnerability was scaled so that, for a specific predator, it summed to 1 over prey species including other food. The vulnerability for other food was as follows, where $I$ was the total number of modelled prey:

$$
\rho_{\text {other }_{j}}=1-\sum_{i=1}^{I} \rho_{i, j} \text {. }
$$

There was an initial abundance at age for each species and annual recruitment at age 1 produced new cohorts [Table 1, Equation (T1.1)]. The expected catch of a given species followed the Baranov equation [Equation (T1.2)] and the instantaneous fishing mortality rate at age [Equation (T1.3)] followed a logistic curve [Equation (T1.4)]. Lower fishing pressure on smaller individuals is typical for fish populations that are caught by trawl gear (Millar and Fryer, 1999). Expected values for abundance indices were a function of fish abundance [Equation (T1.5)] and survey catchability [Equation (T1.6)]. Abundance indices were also assumed to be generated from samples collected by a trawl survey so smaller fish were assumed less likely to be caught in the sampling gear than larger individuals [Equation (T1.7)]. Annual spawning stock biomass (SSB) represented the biomass of mature fish [Equation (T1.8)].

\section{Data simulation}

Input settings: The OMs were configured to simulate annual observations over a 42-year period for two species, modelled with many characteristics of the Georges Bank Atlantic cod (Gadus morhua) and Northwest Atlantic herring (Clupea harengus) populations. The majority of the data streams was simulated giving arbitrary values to the model parameters and inputs. Few inputs to current single species stock assessments and diet data were also used for the stocks to resemble cod and herring. These are described below and the data used corresponded to the years 1973-2014.

The models used the annual weight-at-age, the month of spawning and the proportion of mature fish at age from the Georges Bank Atlantic cod and Atlantic herring stock assessments (Deroba, 2015; Northeast Fisheries Science Center, 2015). In the multispecies models, cod is the only predator and eats cod, herring, and other food. Age classes for both species in the models ranged from 1 to 9 and all older fish were also modelled in pooled age class $(10+)$. Stomach content data from the Northeast Fisheries Science Center (Smith and Link, 2010) were also used to empirically estimate cod per-capita $C R$ and the cod size preference parameters $\alpha$ and $\beta$, which were all then assumed fixed and known in the EMs (i.e. the values in the EMs matched the "correct" values in the OMs). The methods used to obtain these values are detailed in Supplementary Material S1.

To simulate the data necessary for the EMs, values were chosen for the parameters of the OMs so that the predator-prey interactions were strong for the modelled species and population collapse over the modelled time series was avoided. Simulation values for the model parameters and inputs are given in Supplementary Material S2. Cod and herring residual natural mortality rates in the OMs were fixed at 0.2 and 0.35 respectively for all ages and years.

Observation error structure: Given assumed parameter and input values, 1000 sets of stochastic observations were generated

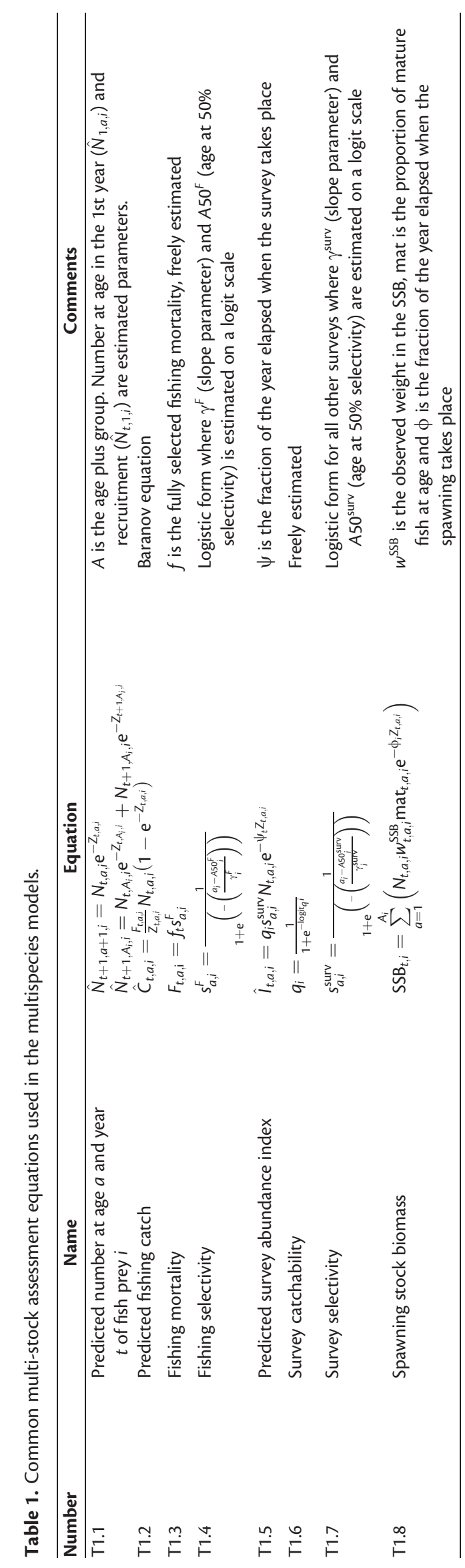


from each OM. The simulated data sets included aggregated catch and abundance indices, age composition data for catch and abundance indices, and predator diet data. Observations were simulated assuming log aggregated catch [Table 2, Equation (T2.1)] and log aggregated survey indices [Equation (T2.2)] were normally distributed with given variance, as is the common practice in Northwest Atlantic stock assessments (Deroba, 2015; Northeast Fisheries Science Center, 2015). Similarly, catch and survey age compositions were assumed to be multinomial distributed [Equations (T2.3) and (T2.4)]. Predator diet observations (stom) consisted of the proportions of each prey species by weight in a predator stomach. We assumed these proportions followed a Dirichlet distribution [Equation (T2.5)].

OM scenarios: Seven OMs were considered with alternative assumptions for the amount of predator diet data, its observation error variance and the intensity of predation on the prey species (Table 3). These OMs were chosen to cover typical problems and possible source of bias that can be encountered when working with diet data. We did not investigate the effect of different levels of noise in observed catch and survey indices or in biological processes on model performance.
OM1 represented an "ideal" situation where the number of samples was large (500 stomachs per year) and the predator-prey interactions were strong such that the modelled prey represented on average $40 \%$ of the predator diet and around 50\% for older predator age groups. OM1 was used as a base case and other OMs were created by varying from this base case.

The importance of the number of diet samples was evaluated by using only 50 (the first 10\%) of the stomachs for OM2.

The effect of variability in the diet data was evaluated by decreasing the Dirichlet parameter $(\kappa)$ to generate diet data with more observation error (larger variance, OM3).

Assuming the proportion of prey by mass in a predator stomach is equivalent to the proportion of prey biomass available in the ecosystem [Equation (T2.5)] meant that, with everything held constant, an increase in the biomass of other food available would increase the biomass of other food eaten by the predator. The effect of the strength of the predator-prey interactions on estimation was assessed with OM4 where predator-prey interactions were reduced by increasing the biomass of other food available such that it represented around $80 \%$ of the predator stomach contents for all simulated data sets.

Table 2. Distributions used for each data type in the multispecies models.

\begin{tabular}{|c|c|c|c|}
\hline Number & Name & Equation & Comments \\
\hline $\mathrm{T} 2.1$ & $\begin{array}{l}\text { Observed aggregated catch in } \\
\text { weight }\end{array}$ & $\log \left(C_{t, i}\right) \mid N_{t, a, i} \sim \mathcal{N}\left(\log \left(\sum_{a=1}^{A_{i}} \hat{C}_{t, a, i} w_{t, a, i}\right), \sigma_{C_{t, i}}^{2}\right.$ & $\sigma_{C}^{2}$ is the observation variance \\
\hline $\mathrm{T} 2.2$ & Observed aggregated survey indices & $\log \left(I_{t, i, k}\right) \mid N_{t, a, i} \sim \mathcal{N}\left(\log \left(\sum_{a=1}^{i} \hat{l}_{t, a, i, k}\right), \sigma_{I_{t, i, k}}^{2}\right.$ & $\sigma_{I}^{2}$ is the observation variance \\
\hline T2.3 & Observed age composition in catch & $\log \left(\frac{C_{t, a, i}}{\sum_{A_{i}} C_{t, a, i}}\right) \mid N_{t, a, i} \sim$ Multinom $\left(\log \left(\frac{\hat{C}_{t, a, i}}{\sum_{A_{i}}^{A_{i}} \hat{C}_{t, a, i}}\right.\right.$ & Multinomial distribution \\
\hline T2.4 & $\begin{array}{l}\text { Observed age composition in survey } \\
\text { indices }\end{array}$ & $\log \left(\frac{I_{t, a, j, k}}{\sum_{a=1}^{A_{i}} I_{t, a, j, k}}\right) \mid N_{t, a, i} \sim$ Multinom $\left(\log \left(\frac{\hat{l}_{t, a, i, k}}{\sum_{a=1}^{A_{i}} \hat{i}_{t, a, i, k}}\right.\right.$ & Multinomial distribution \\
\hline $\mathrm{T} 2.5$ & $\begin{array}{l}\text { Observed prey proportions by } \\
\text { weight in the diet of the } \\
\text { predator }\end{array}$ & $\frac{\sum_{a=1} \Phi_{t, a, n, b, j}}{\text { Фother }_{t, b, j}+\sum_{i=1}^{1} \sum_{a=1}^{A_{i}} \varphi_{t, a, i, b, j}} \sim$ Dirichlet $\left(\frac{\text { stom }_{s, t, n, b, j}}{\sum_{n=1}^{1+1} \text { stom }_{s, t, n, b, j}}, \kappa_{j}\right)$ & $\begin{array}{l}n \text { is the index for prey including } \\
\text { other food. } s \text { represents a specific } \\
\text { stomach. } \kappa_{j} \text { is a parameter for } \\
\text { each predator } j \text {. }\end{array}$ \\
\hline
\end{tabular}

Table 3. Description of the different operating (OM) and estimation (EM) models.

\begin{tabular}{ll}
\hline Name & \\
\hline Operating models & Description \\
OM1 & The diet data consist of 500 stomachs per year \\
OM2 & The diet data consist of 50 stomachs per year such that sample size is reduced by $90 \%$ \\
OM3 & The diet data consist of 500 stomachs per year and the variance in the data is increased \\
OM4 & The diet data consist of 500 stomachs per year and the strength of predator-prey interactions is weakened such that modelled \\
& prey species only represented maximum $20 \%$ of the predator diet \\
OM5 & Diet data are unavailable for the first half of the times series and consist of 500 stomachs per year when they are available \\
OM6 & Diet data are unavailable for predators of ages 7 to $10+$ and consist of 500 stomachs per year when they are available \\
OM7 & The diet data are fitted per stomach every year \\
Estimation models & The diet data are fitted every year to the mean stomach content taken over the stomach of a predator of age $a$ \\
EM1 & The diet data are fitted to the 10 years aggregated mean content taken over the stomach of a predator of age $a$ \\
EM2 & The diet data are fitted to the entire time series aggregated mean content taken over the stomach of a predator of age $a$ \\
EM3 &
\end{tabular}


Often, diet data are not available for the entire time series. There exist numerous ways data availability could be tested. For simplicity, in OM5, we assumed that diet data were not available for the first half of the modelled time series, but predation was still modelled over the entire model time frame. Since the predation parameters are not year-dependent in the model, it may still be possible to estimate them despite stomach data unavailability. This scenario tests if missing diet data in some years would affect model estimation. This model would for example corresponds to an ecosystem where surveys for stomach content collections were implemented only from the middle of the time series.

Finally, OM6 and OM7 tested the consequences of missing samples for certain predator age classes which is typical during research surveys. For simplicity, OM6 assumed young predators (ages 1-4) were not sampled over the entire time series and OM7 assumed older predators (ages 7 to $10+$ ) were not sampled.

\section{Estimation models}

\section{Parameter estimation}

The statistical catch-at-age models shared the same model structure as the OMs. Predicted total catch, total survey abundance indices, age compositions for catch and indices and proportions of prey in the predator diet were fitted to annual observations obtained from the OMs assuming the statistical distributions used to simulate the observation data [Equations (T2.1)-(T2.5)].

Estimated model parameters included fishing parameters (fully selected annual fishing mortality $f_{t}$ and parameters governing selectivity at age $\gamma^{F}$ and $A 50^{F}$ ), survey abundance index parameters (survey catchability $q$ and selectivity at age parameters, $\gamma^{\text {surv }}$ and $\left.A 50^{\text {surv }}\right)$, the abundance at age in the first year $\left(N_{1, a}\right)$, annual recruitment at age $1\left(N_{t, 1}\right)$, the predation parameters (general vulnerability $\rho$ and Dirichlet distribution parameter $\kappa$ ) and residual natural mortality per prey species $\left(M_{i}\right)$. $M$ being constant across ages and years in the OMs, only one value of $M$ is estimated by prey species in the EMs. This gave a total of 201 parameters (Supplementary Material S2).

\section{EM scenarios}

Four EMs were fitted to the 7 OMs (Table 3). EM1 represented the same configuration as the OMs. Each diet observation (stomach) was fitted using Equation (T2.5).

EM2 was a simplification where diet observations were averaged over stomachs for predators of a specific age, resulting in only one data point per predator age and year $[s=1$ in Equation (T2.5)]. Individual predator diet observations are rarely fitted to in multispecies models applied to fish populations, often due to the limited number of diet observations available.

In EM3, the model was simplified further by averaging diet observations and corresponding predictions for each predator age over 10-year intervals. Aggregating diet over time is sometimes used when the number of annual samples is deemed insufficient. In their studies, Van Kirk et al. (2010) and Curti et al. (2013) aggregated the diet observations across a 7 year and 5 year period, respectively. Sensitivity tests aggregating the diet over 5-year intervals did not change the magnitude of the bias in this study.

Finally, EM4 predicted and fitted to the mean diet proportions aggregated over the entire time series. Performance of models EM3 and EM4 should provide insight on the effect of aggregating the diet data over time.

\section{Sensitivity analysis}

The OM4 scenario produced unexpected results, which will be presented later, that led to running an extra OM4-EM1 simulation with reduced variance around the diet observations.

In the OMs, the annual fully selected fishing mortality $(f)$ was kept constant which may seem unrealistic. The sensitivity of the model to this assumption was assessed by running two scenarios. In the first one, $f$ varied randomly between 0.1 and 0.9 . In the second scenario, $f$ presented an increasing trend from 0.1 to 0.9 for the first 19 years, then was constant at 0.9 for 5 years, then decreased for the remaining years to reach 0.1. EM1 and EM2 were fitted to these two sensitivity scenarios.

The 7 OMs allow the effect of possible sources of bias in stomach data to be investigated separately. In real ecosystems, these sources of bias may happen jointly. As it is not possible to investigate all possible OM combinations, we chose to run an additional OM8 that combined OM3 and OM4 where the interactions were weak and the stomach data had larger variance. This run is likely a more realistic representation of ecosystems where many different prey are consumed by predators and stomach data are noisy.

Finally, we ran the OM1 scenario estimating residual natural mortality at age in the EMs to see if it was possible to estimate consistent $M$ at age values when no observed data are available to inform them.

\section{Performance metrics}

Each of the four EMs was fitted to the 1000 data sets for each OM. Performance of the EMs was calculated using the estimated median relative difference (RD) as a measure of estimation bias:

$$
\mathrm{RD}=\frac{\hat{\theta}}{\theta}-1
$$

where the true value of the parameter or derived output was $\theta$ and the estimated values were $\hat{\theta}$. Here, we focused on model bias as a measure of performance but we did not investigate performance in terms of parameter uncertainty. For time and agevarying parameters, the $\mathrm{RD}$ was estimated at each year and age. The $95 \%$ confidence intervals of the median $\mathrm{RD}$ were also estimated using the binomial distribution method of Thompson (1936).

For conciseness, we focused on presenting the results for parameter estimates and outputs used in management of fish populations: SSB, recruitment, $F, M$, and $P$. To enable comparison of all EMs, the results were presented as boxplots of the median RD. Age and (or) time-varying outputs were aggregated into one boxplot, which did not represent the true variability of each annual and age-specific estimate. However, these summaries sufficed to convey underlying conclusions since the variability in bias was generally small for each age and year. For comparison, the full diagnostics presenting the median $\mathrm{RD}$ with $95 \%$ confidence intervals disaggregated by year and age for all parameters and outputs are given in Supplementary Material S3.

\section{Results}

In the base case (OM1), all EMs performed well with a bias of less than $2 \%$ (Figure 1). Fishing, predation, and natural mortality were well estimated. The $95 \%$ confidence intervals around the median RD for $M$ increased for EM3 and EM4 but the range was still of only a few percent. 


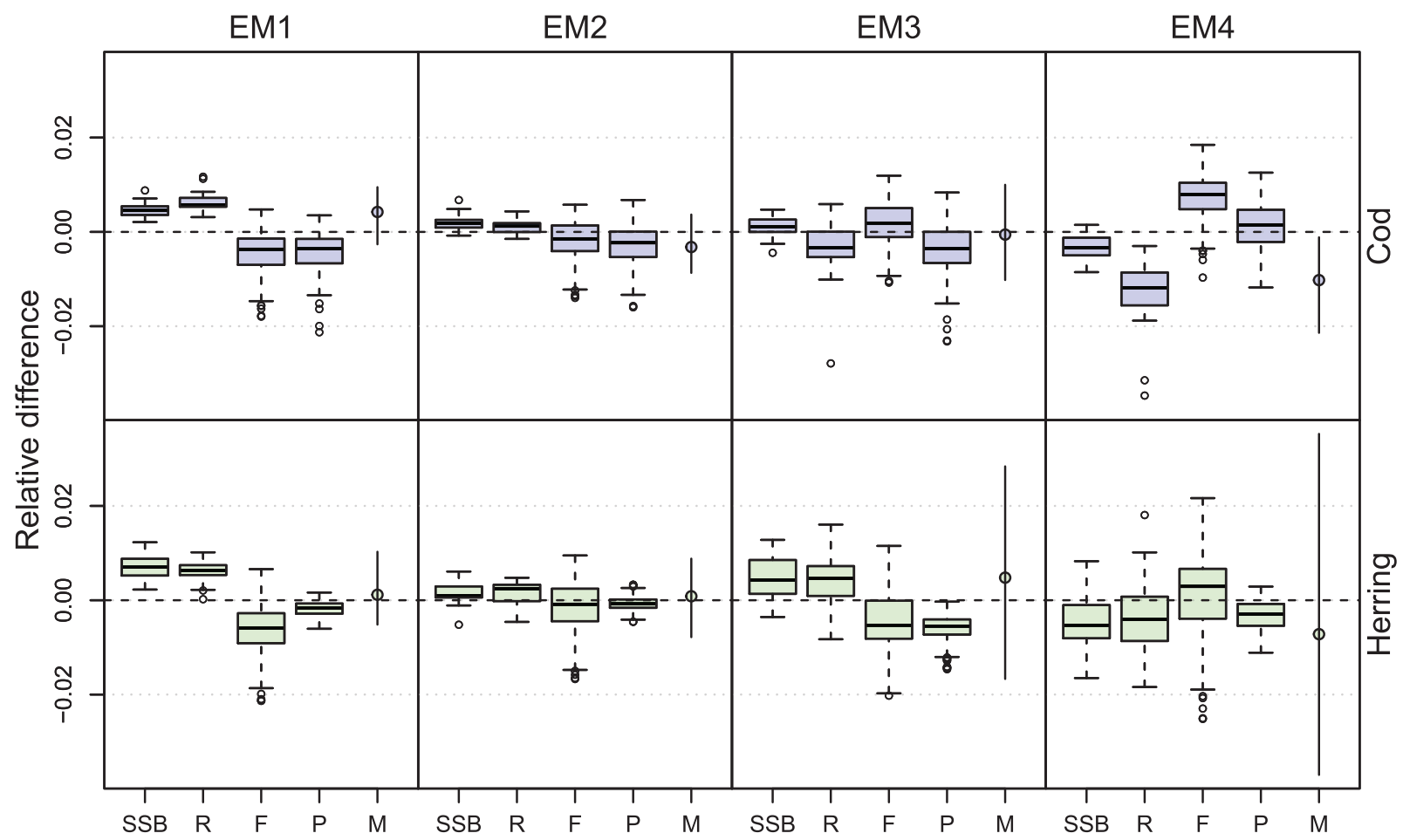

Figure 1. Median RDs for SSB, recruitment $(\mathrm{R})$, fishing mortality $(F)$, and predation mortality $(P)$ for the fit to OM1, the base case scenario. One value is estimated for residual natural mortality $(M)$, so the median RD and its $95 \%$ confidence interval are presented for $M$.

When the number of stomachs is reduced by $90 \%$ (OM2), estimation bias increased when the diet was aggregated over time (EM3 and EM4, Figure 2). Maximum bias for EM3 ranged between 5 and $10 \%$ although this increased to almost $20 \%$ for $M$ when using EM4. Both EM3 and EM4 had difficulty estimating cod recruitment in the final year (Supplementary Figure S4.1, see also Supplementary Material S3). Reducing the number of stomachs by $90 \%$ in this manner did not affect estimation for EM1 and EM2.

Increasing the variance in the diet data (OM3) mainly affected EM1, with a median bias for all outputs between 0.8 and $7 \%$ (Figure 3). Estimates from EM1 were increasingly biased (2-77\%) when the interactions between cod and the modelled prey were weak (OM4, Figure 4). Fitting EM4 to the OM4 data resulted in a smaller but still large bias (1-37\%) across all parameters and outputs, mainly for cod. The bias decreased $(<2 \%)$ for the configuration OM4-EM1 when the variance in the diet data was reduced (Figure 5), highlighting that the bias may be due to diet proportions being too often at the lower bound of the Dirichlet distribution (i.e. 0) since using averaged diet proportions (EM2) reduced this problem (Figure 4).

Removing the first half of the diet data time series resulted in a large bias in the EM4 cod fishing mortality of around 50\% due to estimated $M$ approaching zero (Figure 6). The bias on $\operatorname{cod} F$ increased with decreasing cod size or age with bias around 100\% in $F$ at age 1 against around $38 \%$ at age $10+$ (see p. 489 in Supplementary Material S3). In contrast, EM1 and EM2 performed well in this scenario, with EM3 having a larger bias (around 5\%) notably for herring recruitment and SSB (Supplementary Figure S4.3).

Missing stomach samples for young (OM6, Figure 7) or old (OM7, Figure 8) cod did not affect the performance of the EMs much.
The bias in model estimates was overall smaller than $4 \%$ but increased for cod recruitment in the final years of the times series for EM4 (outliers in Figure 8, see also p. 687 in Supplementary Material S3).

The effect of data availability and quality on the performance of the models is best evaluated by comparing results across OMs for each EM. For easy comparison, the RDs for the EMs fitted to all OMs were plotted in Supplementary Figures S4.4-S4.7. While looking at the bias for EM1, EM3, and EM4 it seems that diet data could play a role in model performance since the bias varied between OMs. However, for the EM2 the bias was below 3\% for all OMs, therefore, the diet data scenarios tested did not affect the performance of the multispecies model when the diet data was fitted with EM2.

The results of the sensitivity analysis around the assumption of constant fully selected fishing mortality are given in Supplementary Material S5 (part 1). The bias in EM1 and EM2 was below $2 \%$ in all cases showing that the models were robust to the assumption of constant $f$.

Combining OM3 and OM4 increased the bias in all EMs (Supplementary Material S5, part 2). The largest bias was for EM1, similarly to what was observed in Figures 3 and 4, notably for cod recruitment and herring predation mortality (Supplementary Figure S5.5). The EM2-EM4 presented similar bias with impossibility of estimating correct values of cod residual natural mortality, which was estimated to be null while cod fishing and predation mortality were overestimated by around $50 \%$ (Supplementary Figure S5.6). However, the bias was reduced for all EMs when the residual natural mortality was not estimated in the EMs and fixed at the correct value (Supplementary Figure S5.7). Only EM4 and EM5 presented some difficulty in estimating recruitment for both species in the final years of the time series, highlighted by the outliers in Supplementary Figure S5.7. 


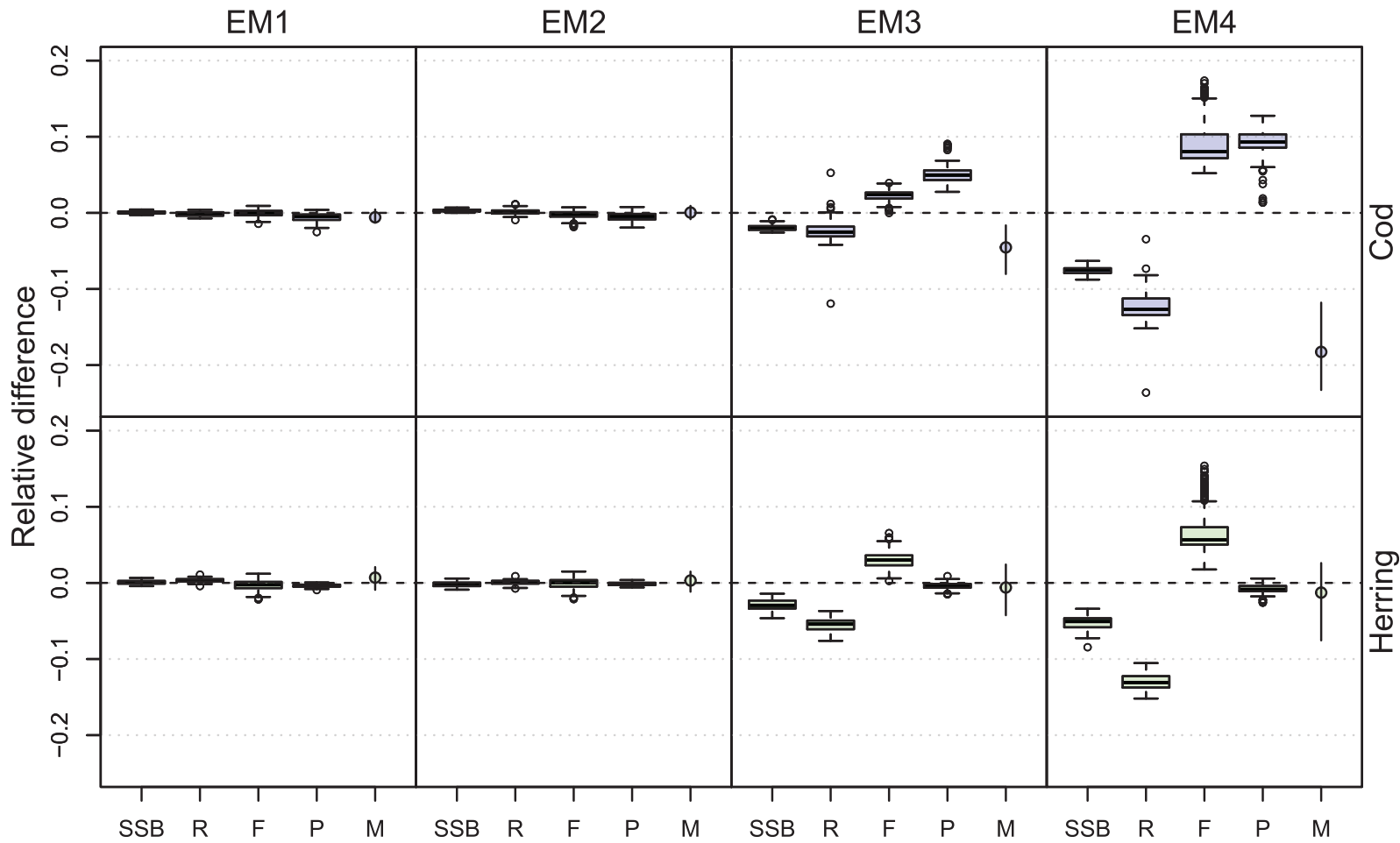

Figure 2. Median RDs for SSB, recruitment (R), fishing mortality $(F)$, and predation mortality $(P)$ for the fit to OM2 when the diet data is reduced to 50 stomachs ( $10 \%$ of original sample size). One value is estimated for residual natural mortality $(M)$, so the median RD and its $95 \%$ confidence interval are presented for $M$. The figure does not present the outlier at -1 for EM 3 and EM4 cod recruitment for comparison purpose. The original figure can be found in Supplementary Figure S4.1.

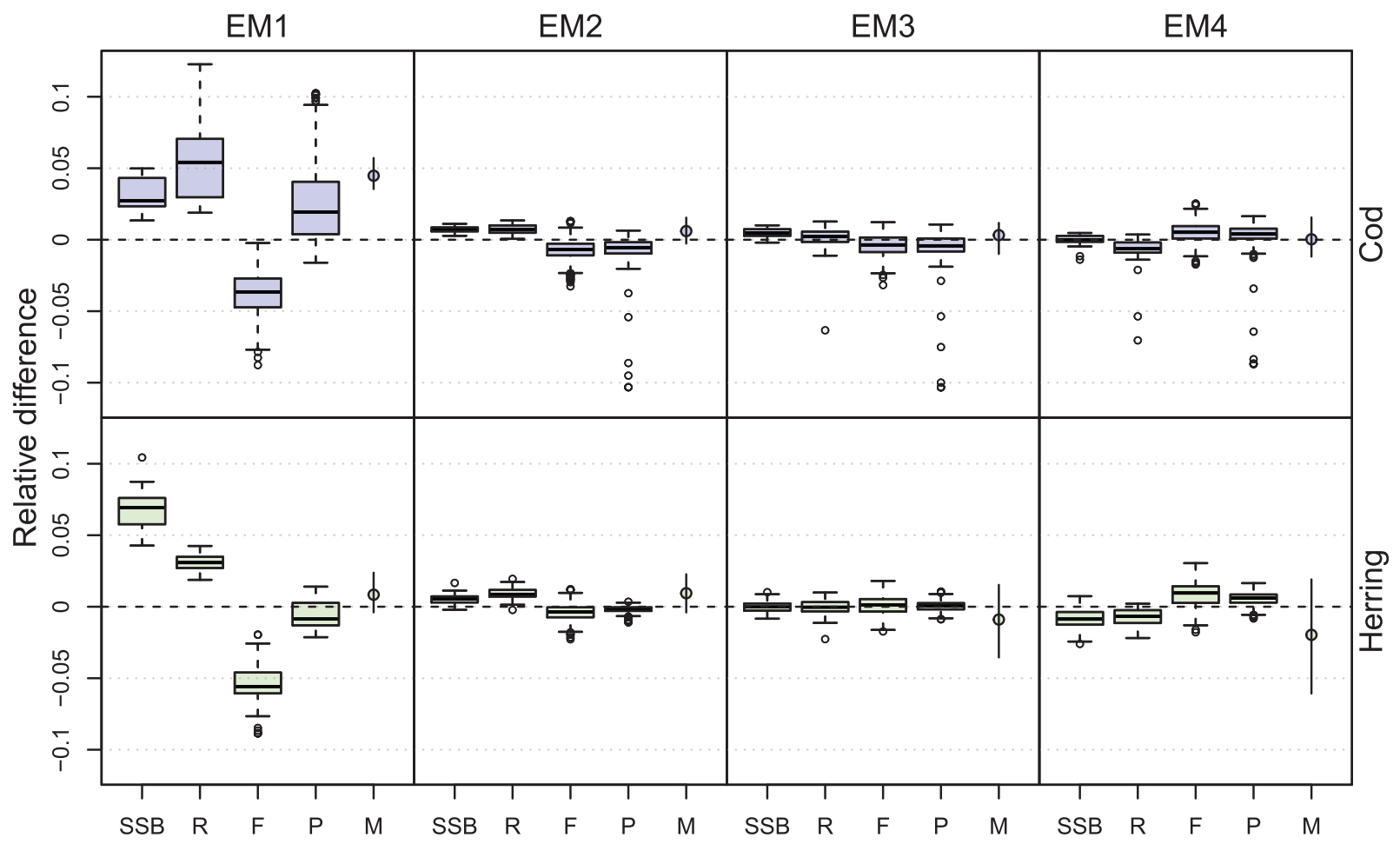

Figure 3. Median RDs for SSB, recruitment $(R)$, fishing mortality $(F)$, and predation mortality $(P)$ for the fit to $O M 3$, where the variance in the diet data is increased compared to the base case. One value is estimated for residual natural mortality $(M)$, so the median RD and its $95 \%$ confidence interval are presented for $M$. The figure does not present the outlier around -0.55 for $E M 4$ cod recruitment for comparison purpose. The original figure can be found in Supplementary Figure S4.2. 


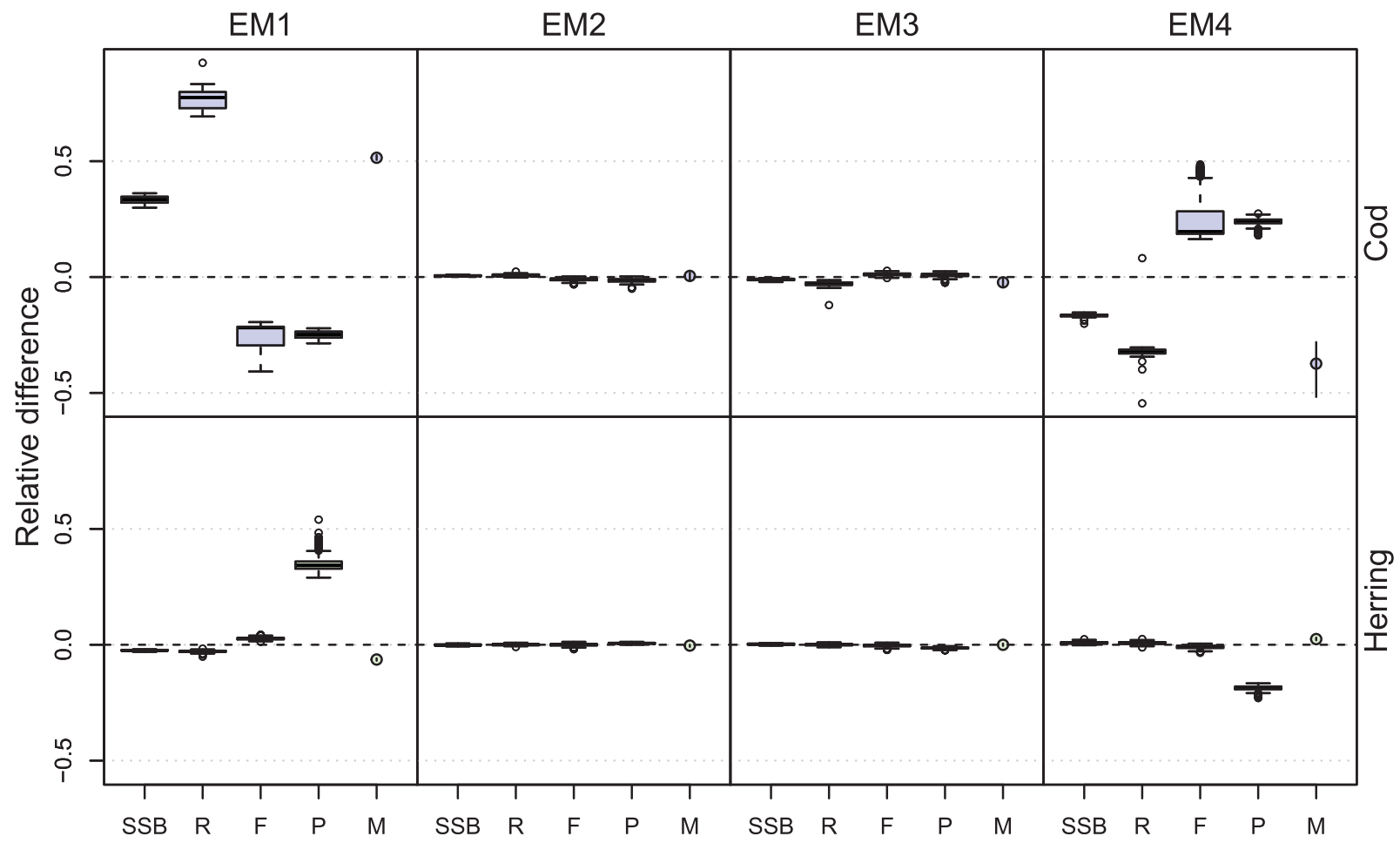

Figure 4. Median RDs for SSB, recruitment $(R)$, fishing mortality $(F)$, and predation mortality $(P)$ for the fit to OM4, where the predatorprey interactions are reduced compared to the base case. One value is estimated for residual natural mortality (M), so the median RD and its $95 \%$ confidence interval are presented for $M$.

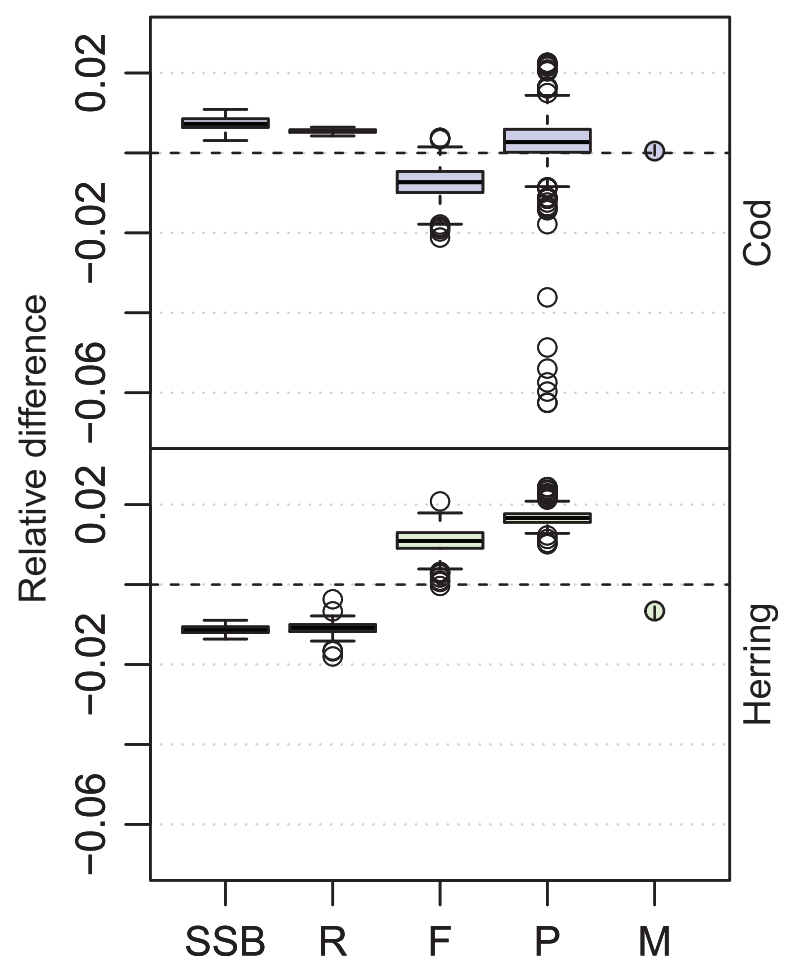

Figure 5. Median RDs for SSB, recruitment (R), fishing mortality $(F)$, and predation mortality $(P)$ for EM1 fitted to OM4, where the predatorprey interactions are reduced compared to the base case but where the variance in the diet data has also been decreased to avoid zeros in diet observations. One value is estimated for residual natural mortality $(M)$, so the median RD and its $95 \%$ confidence interval are presented for $M$.
Estimating residual natural mortality at age induced an increase in the bias for all EMs (Supplementary Material S5, part 3) compared to Figure 1 . The bias was overall above $20 \%$ for all outputs, except for predation mortality and for EM2 that performed best compared to the others EMs. Residual natural mortality presented the largest boxplot highlighting the difficulty in estimating it. For all EMs, $M$ was overestimated and $F$ was underestimated.

\section{Discussion}

For the OMs tested, it is clear that aggregating the diet data over the entire time series should be avoided since it induces bias in the estimation of multispecies models. EM4 performed only for the base case and the OMs 6 and 7 where a lot of stomachs were available every year and the interactions between prey and predator were large. For other OM scenarios, estimation bias was substantial for all parameters and derived outputs, sometimes of more than $50 \%$. Similar patterns were observed when the diet data were aggregated every 10 years but to a smaller extent since the bias was mostly below $10 \%$. A problem arises when diet data are not available every year or when the annual sample size is low. In these cases, stomach content data are often averaged over time (Tsou and Collie, 2001; Tyrrell et al., 2008) to reduce variations due to observation errors and remove possible outliers. In this study, we showed that using this method induced a bias to the results while data availability and quality do not notably affect model bias when the data are fitted every year (EM2). It is preferred to use noisy annual stomach data, to avoid precise but biased estimation of affected parameters. Reducing noise at the expense of increasing bias is therefore a bad trade off. These conclusions differ from the study of Van Kirk et al. (2015) which showed that uninformative diet affects multispecies model 


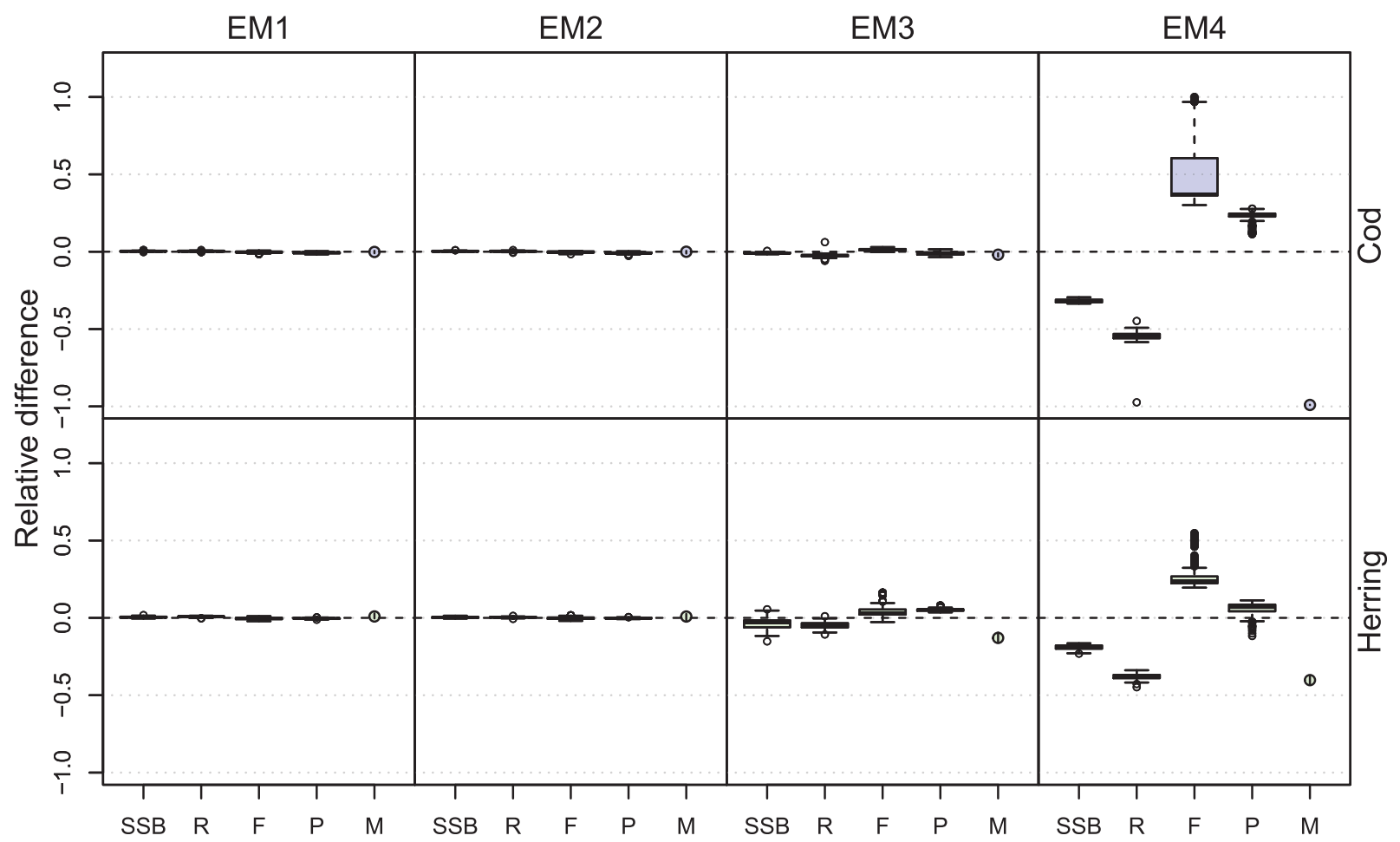

Figure 6. Median RDs for SSB, recruitment $(R)$, fishing mortality $(F)$, and predation mortality $(P)$ for the fit to OM5, where the first 21 years of diet data have been ignored. One value is estimated for residual natural mortality $(M)$, so the median RD and its $95 \%$ confidence interval are presented for M. A supplementary figure showing the results for EM1-EM3 only (for better comparison) is provided in Supplementary Figure S4.3.

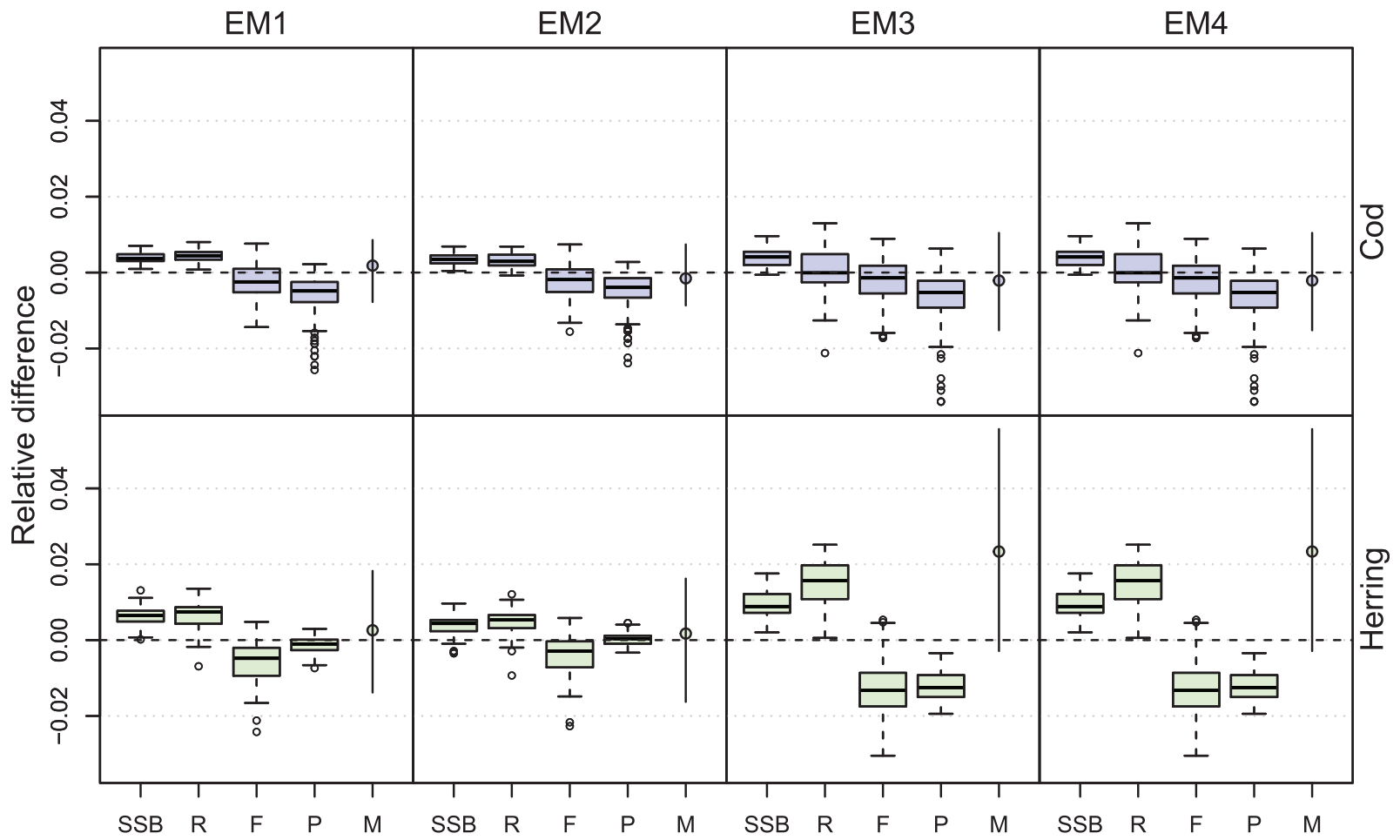

Figure 7. Median RDs for SSB, recruitment $(R)$, fishing mortality $(F)$, and predation mortality $(P)$ for the fit to OM6, where the diet data for cod of ages 1-4 is not available. One value is estimated for residual natural mortality $(M)$, so the median RD and its $95 \%$ confidence interval are presented for $M$. 


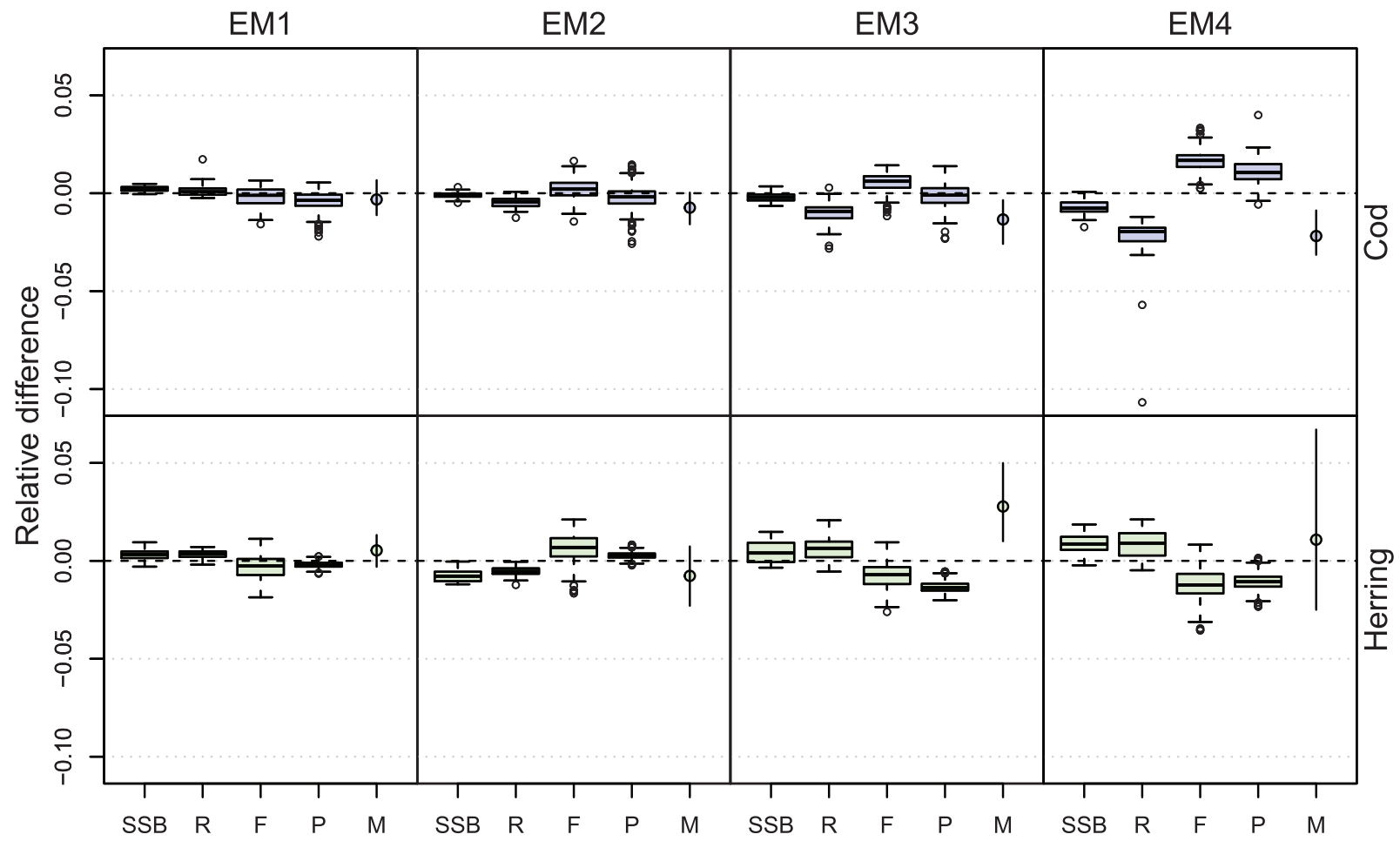

Figure 8. Median RDs for SSB, recruitment $(R)$, fishing mortality $(F)$ s and predation mortality $(P)$ for the fit to OM7, where the diet data for cod of ages 7 to $10+$ is not available. One value is estimated for residual natural mortality $(M)$, so the median RD and its $95 \%$ confidence interval are presented for $M$.

performance. However, the Van Kirk et al. (2015) paper aggregated the diet data by 7 -year intervals, which may induce bias into the results (Deroba, 2018) since we demonstrated that the estimation bias increased when multiple model misspecifications are made as shown in Supplementary Figures S4.4, S4.6, and S4.7 and when different sources of bias are combined Supplementary Figures S5.5 and S5.6. Here we showed that EM2 performs well even if the number of samples is small, the interactions are weak, or some sampled years and ages are missing. While EM1 performs well in most cases, bias can be introduced when the interactions are weak or diet data is too noisy and EM2 performs better overall. This method (fitting to mean annual observations) should therefore be preferred when fitting multispecies models.

Effective multispecies models should be guided by the predator-prey interactions for informing model dynamics (Link, 2002); a lack of information for some processes may lead to poor model performance. However, small bias was observed for all EMs when the diet data were unavailable for young or old predators (OM6 and OM7). Compared to common single species assessment models, the EMs in this study estimated prey vulnerability $(\rho)$ and residual natural mortality $(M)$ but the $C R$ and size preference parameters ( $\alpha$ and $\beta$ ), that are informed by predator diet data, were estimated empirically and fixed in the EMs. Prey vulnerability is not age dependent in this study so existing data allow estimation of accurate vulnerability and therefore predation for all ages despite missing observations for some age classes. These results indicate accurate estimates of prey vulnerability together with known size preference parameters and CR can likely be obtained, even if samples are only available for some age classes. In systems where prey vulnerability may vary by age due, for instance, to age dependent spatial overlap, missing data on specific age classes may become a limitation and these results may not be relevant.

Although model misspecification is a common source of bias in simulation testing, we found that an incorrectly specified model outperformed a correctly specified one. The EM1, which has the same configuration as the OMs, gave more biased results than the EM2 in some cases (OM3 and OM4). At first glance, this result is unexpected since one would expect EM1 to perform best since it matches the OMs. The difference for EM1 compared to the other EMs is that the diet data is fitted per stomach instead of the annual averaged stomach content per predator age. During the simulation process, the predicted diet proportions in the OMs are used to simulate observed stomach contents using the Dirichlet distribution. Due to computing rounding limits, a very small predicted diet proportion for a specific prey may result in the absence of this prey in the observed simulated stomach instead of a really small proportion. This means that when the simulated data are fitted, the EM may predict a very small but nonzero proportion for an observed proportion that is null. Since the Dirichlet cannot handle zeros in predictions or observations, when a prey is absent in an observed stomach, this particular proportion is not fitted and therefore does not enter the loglikelihood calculation. In the OM3 and OM4, the increase in the diet data variance or weakened predator-prey interactions resulted in a large proportion of zeros in observations (given more predictions in the OMs close to 0 ) while the predictions are non-zero in the EMs. For these cases, there is an increased number of non-fitted predictions that should be fitted but are not because the corresponding observed proportion is null. This is enough to cause a bias in the estimation process. The absence of bias in the case of weak interactions but small diet data variance 
(Figure 5), which reduced the number of positive close to zero predictions for null observations, shows evidence that EM1 performs well if this problem of zeros does not occur. Fitting the diet data per stomach may therefore be problematic if the data contains a large number of null observations. Using a Delta-Dirichlet distribution which allows for zeros could solve this, but also increases the number of parameters to estimate. Averaging the stomach content data across stomachs every year, which removes these zeros, may be an easier alternative. In our simulation, this method showed unbiased results as well as faster optimizations.

The results for EM1 and EM2 may initially seem unrealistically precise. In any case, we make no claim that these levels of bias could be achieved in reality, rather we are concerned with investigating relative changes in bias between the different scenarios analysed here. The process and observation error variances used to simulate data in the OMs were chosen so they are of the same order of magnitude with what is usually used or estimated in stock assessments; therefore, these results are not due to unrealistically low levels of errors. Also, the figures presented here only showed the distribution of median bias. The distributions in bias with $95 \%$ confidence intervals, which were slightly larger, are provided in the Supplementary Material S3. Presenting the 95\% confidence interval around the median bias rather than the quartiles around the bias distribution also reduced the perception of the variation across the 1000 iterations. In the OMs, the simulated mean observed stomach content varied annually (Supplementary Figure S4.8) but maybe not at much as in reality (Deroba, 2018) so the bias may be worse for more variable diets. Also, for simplicity, predator size preference parameters and CR were estimated empirically and assumed known and constant over time in our study. As mentioned earlier, using known values for cod CR and size preference parameters may help model precision since only vulnerability and residual natural mortality need to be estimated compared to single species assessments.

Predator CRs can be estimated following predator energetic requirements (Essington et al., 2001) or as a function of predator evacuation rate and daily ration (Durbin et al., 1983). Here, the latter method was used and the resulting CR is highly dependent on the assumed gastric evacuation parameters (Supplementary Material S1). While it did not matter for this simulation study that focuses on performance of multispecies models as a function of diet data, it may be important to explore different values for these parameters when the model is applied to a real ecosystem. A sensitivity analysis around the parameters used to estimate the gastric evacuation rate could be conducted (Tsou and Collie, 2001) but another option would be to estimate the predator CRs within the assessment model. Size preference parameters ( $\alpha$ and $\beta$ ) could also be estimated within the model simultaneously using observed data on predator mass and prey mass in the predator stomach. It would be interesting to treat CR and size preference as parameters that would be informed by diet data or by a prior distribution. This approach would account for parameter uncertainty within the model and also allow the possibility of simulating these parameters within the OMs. However, doing so will increase the number of estimated parameters. In real ecosystems, $\mathrm{CR}$ and size preference can vary within a year and stomach data is rarely collected all months of the year. This study did not consider the possible bias resulting from misestimating annual values of consumption and selectivity, which may also be important.

The biomass of other food is an important assumption in multispecies models. Assuming this biomass constant is a standard procedure but this is a potential source of bias since this can greatly affect the model outputs and is also highly uncertain. This limitation was not investigated in the models. The biomass of other food was notably used in the model to vary the importance of predator-prey interactions between the modelled prey. For ecosystems where the biomass of other food is very large compared to the biomass of modelled prey, a small change in the biomass of other food will not affect the results (Curti et al., 2013) but larger changes and uncertainties may have a significant effect. The biomass of other food is difficult to estimate in real ecosystems and more work should be spent in estimating possible proxies for this value.

Fishing mortality was assumed constant over time but still estimated annually. This assumption does not affect the bias in the results as shown in Supplementary Figures S5.3 and S5.4, where the fully selected fishing mortality $(f)$ varied annually in the OMs (Supplementary Figures S5.1 and S5.2). The multispecies models created managed to differentiate between variation in fishing and predation mortality.

In this simulation study, we modelled two species, one predator and two prey, resulting in 201 estimated parameters. Model performance may change if more fish species are considered in the model since this would increase the number of estimated parameters, although the amount of diet data would also be increased. Also, residual natural mortality, while an estimated parameter, was assumed to be constant across ages and years. This results in only one value of $M$ estimated per prey species. However, the estimation bias increased when $M$ was estimated to vary by age due to no additional observed data being available to inform them. For EM2, the median bias was below $20 \%$, which is fairly good for a parameter not informed directly by the observations. However, we might expect bias to increase when sources of bias are introduced to the diet data. In Supplementary Figure S5. 8 (OM8), even when $M$ was estimated at age the true value was constant across ages since we used the data sets simulated with OM1. Bias may increase further if $M$ was age and time-varying in the OM. How informative the diet data need to be to allow estimation of varying $M$ is worth investigating in the future. Statespace approaches may offer a means to account for non-observed mortality via process errors and may mitigate the problem of a lack of data to inform $M$.

Finding the balance between model complexity and increasing bias is one of the challenges for EBFM (Collie et al., 2016); multispecies models of intermediate complexity, such as the one presented here, are found particularly relevant in this context (Plagányi et al., 2014). Our multispecies assessment models can successfully estimate mortality rates and correctly partition the total mortality into fishing, predation, and residual natural mortality from the data sets examined here. This provides evidence that simple multispecies statistical catch-at-age models can be augmented from single species statistical catch-at-age models with minimal added complexity by fitting to diet data where they are available. The real difficulty in practice is to obtain the diet data needed to develop these types of models. Many ecosystems suffer from lack of diet data. While stomach content data are collected annually in the United States since 1973 (Smith and Link, 2010), in comparison, only 4 years of diet data are available in the North Sea (ICES, 1997). The data simulated here may be more exhaustive that what is currently available for certain ecosystems and, when multiple sources of bias are introduced, the bias increases. There is therefore a real need in obtaining stomach 
content data in the future to inform multispecies models and improve EBFM. Fitting the annual stomach content (EM2) is robust even when few stomachs are collected, predator ages are missing or the interactions are weak. Also, EM2 provides good estimates over the entire time series even when the first half of the time series is missing. The regular collection of diet data in the future could therefore allow the estimation of past and present predation mortality.

\section{Supplementary data}

Supplementary material is available at the ICESJMS online version of the manuscript.

\section{Acknowledgements}

We thank Jon J. Deroba and Robert J. Gamble as well as two anonymous reviewers for their helpful comments on the manuscript.

\section{Funding}

This project was funded by NOAA Fisheries' FY16 Stock Assessment Analytical Methods internal request for proposal.

\section{References}

Andersen, K. P., and Ursin, E. 1977. A multispecies extension to the Beverton and Holt theory of fishing, with accounts of phosphorus circulation and primary production. In Meddelelser Fra Danmarks Fiskeri- OG Havundersogelser, pp. 319-435. Ed. by J. M. Christensen, E. Ursin and E. Hoffmann. The Danish Institute for Fishery and Marine Research, Copenhagen.

Christensen, V., and Walters, C. J. 2004. Ecopath with Ecosim: methods, capabilities and limitations. Ecological Modelling, 172: 109-139.

Collie, J. S., Botsford, L. W., Hastings, A., Kaplan, I. C., Largier, J. L., Livingston, P. A., Plagányi, É. et al. 2016. Ecosystem models for fisheries management: finding the sweet spot. Fish and Fisheries, 17: 101-125.

Curti, K. L., Collie, J. S., Legault, C. M., and Link, J. S. 2013. Evaluating the performance of a multispecies statistical catch-at-age model. Canadian Journal of Fisheries and Aquatic Sciences, 70: 470-484.

Deroba, J. J. 2015. Atlantic herring operational assessment report 2015. Ed. by US Department of Commerce. Northeast Fisheries Science Center Reference Documents 15-16. 30 pp.

Deroba, J. J. 2018. Sources of variation in stomach contents of predators of Atlantic herring in the Northwest Atlantic during 1973-2014. ICES Journal of Marine Science, 75: 1439-1450.

Dolan, T. E., Patrick, W. S., and Link, J. S. 2016. Delineating the continuum of marine ecosystem-based management: a US fisheries reference point perspective. ICES Journal of Marine Science, 73: $1042-1050$

Durbin, E., Durbin, A., Langton, R., and Bowman, R. 1983. Stomach contents of silver hake, Merluccius bilinearis, and Atlantic cod, Gadus morhua, and estimation of their daily rations. Fishery Bulletin, 81: 437-454.

Essington, T. E., Kitchell, J. F., and Walters, C. J. 2001. The von Bertalanffy growth function, bioenergetics, and the consumption rates of fish. Canadian Journal of Fisheries and Aquatic Sciences, 58: 2129-2138.

FAO Fisheries Department. The ecosystem approach to fisheries. FAO Technical Guidelines for Responsible Fisheries. No. 4, Suppl. 2. Rome, FAO. 2003. 112 pp.

Fulton, E. A., Smith, A. D. M., and Johnson, C. R. 2004. Effects of spatial resolution on the performance and interpretation of marine ecosystem models. Ecological Modelling, 176: 27-42.
Fulton, E. A., Smith, A. D. M., Smith, D. C., and Johnson, P. 2014. An integrated approach is needed for ecosystem based fisheries management: insights from ecosystem-level management strategy evaluation. PLoS One, 9: e84242.

Gislason, H., and Helgason, T. 1985. Species interaction in assessment of fish stocks with special application to the North Sea. Dana, 5: 1-44.

Grüss, A., Harford, W. J., Schirripa, M. J., Velez, L., Sagarese, S. R., Shin, Y.-J., and Verley, P. 2016. Management strategy evaluation using the individual-based, multispecies modeling approach OSMOSE. Ecological Modelling, 340: 86-105.

Hawkins, D. M. 2004. The problem of overfitting. Journal of Chemical Information and Computer Sciences, 44: 1-12.

Helgason, T., and Gislason, H. 1979. VPA-analysis with species interaction due to predation. International Council for the Exploration of the Sea, Demersal Fish Committee, ICES CM 1979/ C:52.

Holling, C. S. 1959. The components of predation as revealed by a study of small-mammal predation of the European pine sawfly. The Canadian Entomologist, 91: 293-320.

ICES. 1997. Database report of the stomach sampling project 1991. 422 pp. ICES Cooperative Research Report No. 219.

Jurado-Molina, J., Livingston, P. A., and Ianelli, J. N. 2005. Incorporating predation interactions in a statistical catch-at-age model for a predator-prey system in the eastern Bering Sea. Canadian Journal of Fisheries and Aquatic Sciences, 62: 1865-1873.

Kinzey, D., and Punt, A. E. 2009. Multispecies and single-species models of fish population dynamics: comparing parameter estimates. Natural Resource Modeling, 22: 67-104.

Kristensen, K., Nielsen, A., Berg, C. W., Skaug, H., and Bell, B. M. 2016. TMB: automatic differentiation and Laplace approximation. Journal of Statistical Software, 70: 1-21.

Lewy, P., and Vinther, M. 2004. A stochastic age-length-structured multispecies model applied to North Sea stocks. ICES CM 2004/ FF: 20.

Link, J. 2010. Ecosystem-based Fisheries Management: Confronting Tradeoffs. Cambridge University Press, New York.

Link, J. S. 2002. Ecological considerations in fisheries management: when does it matter? Fisheries, 27: 10-17.

Millar, R. B., and Fryer, R. J. 1999. Estimating the size-selection curves of towed gears, traps, nets and hooks. Reviews in Fish Biology and Fisheries, 9: 89-116.

NOAA. 2016. Ecosystem-Based Fisheries Management Policy of the National Marine Fisheries Service National Oceanic and Atmospheric Administration. Ed. by Department of Commerce. National Marine Fisheries Service Policy Directive 01-120. 8 pp.

Northeast Fisheries Science Center. 2015. Operational assessment of 20 northeast groundfish stocks, updated through 2014. Ed. by US Department of Commerce. Northeast Fisheries Science Center Reference Documents 15-24. 251 pp. https://www.nefsc.noaa.gov/ publications/crd/crd1524/.

Plagányi, É. E. 2007. Models for an ecosystem approach to fisheries. Ed. by Food and Agriculture Organization of the United Nations. FAO Fisheries Technical Paper, 477, Rome. 108 pp.

Plagányi, É. E., Punt, A. E., Hillary, R., Morello, E. B., Thébaud, O., Hutton, T., Pillans, R. D. et al. 2014. Multispecies fisheries management and conservation: tactical applications using models of intermediate complexity. Fish and Fisheries, 15: 1-22.

R Core Team. 2018. R: A Language and Environment for Statistical Computing. R Foundation for Statistical Computing, Vienna, Austria.

Smith, B. E., and Link, J. S. 2010. The trophic dynamics of 50 finfish and 2 squid species on the northeast US continental shelf. Ed. by US Department of Commerce. NOAA Technical Memorandum NMFS-NE-216. 646 pp. https://repository.library.noaa.gov/view/ noaa/3755. 
Thompson, W. R. 1936. On confidence ranges for the median and other expectation distributions for populations of unknown distribution form. The Annals of Mathematical Statistics, 7: 122-128.

Tsou, T.-S., and Collie, J. S. 2001. Estimating predation mortality in the Georges Bank fish community. Canadian Journal of Fisheries and Aquatic Sciences, 58: 908-922.

Tyrrell, M. C., Link, J. S., Moustahfid, H., and Overholtz, W. J. 2008. Evaluating the effect of predation mortality on forage species population dynamics in the Northeast US continental shelf ecosystem using multispecies virtual population analysis. ICES Journal of Marine Science, 65: 1689-1700.
Van Kirk, K. F., Quinn, T. J., and Collie, J. S. 2010. A multispecies age-structured assessment model for the Gulf of Alaska. Canadian Journal of Fisheries and Aquatic Sciences, 67: 1135-1148.

Van Kirk, K. F., Quinn T. J., Collie J. S., and A'Mar Z, T. 2015. Assessing uncertainty in a multispecies age-structured assessment framework: the effects of data limitations and model assumptions. Natural Resource Modeling, 28: 184-205.

Weijerman, M., Fulton, E. A., and Brainard, R. E. 2016. Management strategy evaluation applied to coral reef ecosystems in support of ecosystem-based management. PLoS One, 11: e0152577.

Handling editor: Christos Maravelias 